\title{
Organizações Internacionais e Ajuda Pública Multilateral a Cabo Verde
}

\author{
International Organizations and Multilateral Public Assistance to Cape Verde
}

Vlademiro Furtado ${ }^{1}$

\begin{abstract}
RESUMO: Este artigo examina o papel da Ajuda Pública Multilateral a Cabo Verde desde uma perspectiva político-econômica, isto é, de atribuição de recursos financeiros pelas Organizações Internacionais para o financiamento do desenvolvimento a nível nacional. Assim, a análise incide sobre duas Organizações Internacionais - de âmbito supranacional global e supranacional regional -, das quais Cabo Verde mantém relações de cooperação historicamente datadas quais sejam: o Banco Mundial (BM) e a União Europeia (EU). Neste sentido, o objetivo principal do artigo consiste em analisar como a Ajuda Pública ao Desenvolvimento (APD) tem contribuído para o processo de desenvolvimento do país. Nesta senda, defende-se o argumento de que além do carácter seletivo, a APD multilateral tem contribuído para a perpetuação da dependência externa de Cabo Verde no que tange ao financiamento do seu desenvolvimento. Os dados empíricos disponíveis mostram que, apesar de avultados recursos financeiros provenientes da APD desde a sua independência em 1975, o país ainda não conseguiu construir bases econômicas sólidas que o permita superar a grande dependência financeira externa.
\end{abstract}

Palavras-Chave: Cabo Verde; APD; Organizações Internacionais; BM; UE.

ABSTRACT: This article examines the role of multilateral public aid in Cape Verde since a political and economic perspective with emphases on the public aid catchment to development on the national level. Like this, the analyses fall on two international organizations of supranational global and supranational regional scope, what be: the World Bank (WB) and the European Union (EU) in that Cape Verde keeps cooperation relation historically dated. In this sense, the main objective of this article is to analyse how the official development aid has contributed to the process of country development. In this sense, the main argument advocated is that beyond the selective character, the official development aid multilateral has contributed to the perpetuation of external dependency of Cape Verde in relation to their development financing. The empirical data shows that, despite of the great amount of financial resources received for Cape Verde since it independence in 1975, the country yet did not build a solid economic bases to suppurate the great external financing dependency.

Keywords: Cape Verde; Public Aid; International Organization; WB; EU.

\footnotetext{
${ }^{1}$ Doutor em Ciência Política pela UFRGS. Pesquisador com interesse nos seguintes campos de estudo: sistema internacional, integração regional, cultura política, representação política, sistema eleitoral, sistema partidário e democracia.
} 


\section{INTRODUÇÃO}

Este trabalho se estrutura em torno das temáticas de Organização Internacional e Ajuda Pública ao Desenvolvimento (APD)- amplamente discutidas e divulgadas na literatura especializada sobre Relações Internacionais a partir da segunda metade do século XX. De fato, as inúmeras transformações ocorridas no sistema internacional após o final da segunda Guerra Mundial - causadas, sobretudo, pela emergência de problemas globais e pelo rápido crescimento da interdependência global -, vieram desafiar o tradicional sistema internacional de forças, também designado de sistema de Vestefália, no âmbito do qual os Estados-nacionais se posicionavam como os únicos e principais atores na cena internacional.

Neste âmbito, o artigo se debruça sobre os assim chamados "novos atores internacionais" (BM e EU) que, a par dos Estados Nacionais, acumulam importantes poderes e tomam decisões relevantes sobre problemas globais e/ou regionais enfrentados pelos Estados territoriais. Assim, o objetivo principal deste trabalho consiste em analisar como a APD tem contribuído para o processo de desenvolvimento do país tendo em conta a sua enorme fragilidade e vulnerabilidade endêmica da qual o país enfrenta desde o seu reconhecimento internacional como Estado soberano.

Nesta senda, priorizou-se a perspectiva político-econômica da cooperação para o desenvolvimento da qual a Ajuda Pública ao Desenvolvimento (APD) sobressai como o principal instrumento de promoção desse desenvolvimento. Deste modo, argumenta-se que além do caráter seletivo, a APD multilateral tem contribuído para a perpetuação da dependência externa de Cabo Verde no que tange ao financiamento do seu desenvolvimento. A problemática assim exposta obrigou a utilização da metodologia qualitativa assente na exploração de uma variedade de documentação teórica e empírica visando o cumprimento do objetivo traçado.

\section{PROBLEMATIZAÇÃO DE ORGANIZAÇÕES INTERNACIONAIS: SEU CONCEITO E EMERGÊNCIA NO CENÁRIO INTERNACIONAL}

$\mathrm{Na}$ literatura especializada sobre Relações Internacionais é comum relacionar o surgimento das Organizações Internacionais com o fim da I Guerra Mundial no âmbito do 
qual foi possível a assinatura, em 1919, do Tratado de Versalhes que teria sido responsável pela definição do novo Sistema Internacional baseado nas ideias da paz e da segurança coletiva entre as nações (ARCHER, 2015, p. 3). De fato, essas ideias estão na base da criação da então Sociedade das Nações (SDN) que tinha como objetivo desenvolver a cooperação entre as Nações e garantir a paz e a segurança enquanto preceitos ou valores fundamentais que devem nortear as relações entre as nações.

Contudo, a definição do novo sistema internacional marcada pela criação da sociedade das nações mostrou-se incapaz de suplantar a velha ordem advinda desde o sistema de Vestefália o qual reconhecia os Estados como os únicos e principais atores das relações internacionais. Assim, a criação, em 1945, da Organização das Nações Unidas (ONU) na sequência da experiência não bem sucedida da então Liga ou sociedade das Nações representa a prova de que o sistema de Vestefália ou o sistema de organização internacional assente na figura do Estado territorial revelava-se, cada vez mais, impotente perante o surgimento de novas questões, sobretudo, as de foro econômico, social e ambiental das quais exige-se uma atuação e abordagem coordenada e concertada dada a crescente interdependência do sistema internacional (KEOHANE \& NYE, 2001).

Diversos teóricos sinalizam que na base dessa crescente interdependência internacional se encontra o fenômeno da globalização (ROSENAU, 1992) que tem contribuído para a internacionalização dos problemas sociais à escala planetária. Além disso, parece não subsistirem dúvidas de que esse fenômeno esteja também na gênese da crescente fragmentação verificada no âmbito do poder estatal cuja consequência se traduziu, no decurso da última metade do século XX, na deslocação e/ou mudança do lócus da autoridade dos governos nacionais para entidades atuando em diferentes níveis de ação (ROSENAU, 1992).

Nesta senda, Pierre e Peters (2000) sustentam que as transformações ocorridas no seio do sistema político deram origem a três tipos de mudanças no campo do poder político: Primeiro, a autoridade (poder) tem sido transferida do Estado-nacional para entidades regionais e locais; segundo, para entidades supranacionais globais como são exemplos o Sistema das Nações Unidas e as Instituições Financeiras Globais como o Banco Mundial (BM), o Fundo Monetário Internacional (FMI) e supranacionais regionais como a União Europeia (EU) e a União Africana (UA) e, terceiro, para organizações cuja atuação 
se insere fora do controle da esfera governamental como são os casos das organizações não governamentais (ONG's) que, no decurso do século XX, passaram a exercer um papel de grande relevo na provisão dos bens e serviços públicos.

Posição semelhante é aquela encontrada em Susan Strange (1996) a qual defende que a crescente retração do Estado causada pela contínua diminuição do monopólio do poder do Estado no contexto da emergência da Nova Ordem Global Contemporânea (NOGC) terá fomentado o surgimento de organizações e/ou atores transnacionais que, à semelhança do Estado, passam a acumular poderes e atuar em concertação com o Estado na definição e distribuição de políticas que visam a prossecução do desenvolvimento sustentado.

Neste âmbito, a abordagem tradicional conducente a uma correlação de forças que enfatizava o equilíbrio de poder nas relações internacionais tende a perder terreno a favor da abordagem pluralista que enfatiza a interação multilateral e a cooperação entre os demais atores numa contextura internacional marcadamente interdependente, nas quais as relações se entrelaçam numa teia em que se tecem vários interesses.

De fato, a existência de problemas globais (ROSENAU, 1992) que, a partir da segunda metade do século XX entraram na agenda política global, como a poluição ambiental, o terrorismo, a fome e a pobreza, o comércio internacional, entre outros, com impacto no nível mundial, além de estarem na origem desta crescente interdependência global, contribuíram também para a deslocação da autoridade, ou se quisermos, da tomada de decisão da alçada do Estado-central para organizações com ações de âmbito Supranacional Global e Supranacional Regional.

Assim, Organizações Internacionais como a ONU, o BM e outras de âmbito global e regional se constituem, no cenário internacional, como autênticas entidades jurídicas e multilaterais munidas de poder político, socioeconômico e cultural que, a par de Estados, passam a influenciar e decidir questões de interesse coletivo. Neste contexto, a cooperação multilateral para o desenvolvimento passa a ser encarada como uma alternativa viável ao tradicional modo de agregação, na qual os Estados-nacionais se posicionavam como os únicos e principais atores na cena política internacional. 
Aliás, como salienta Carrillo Salcedo (1984, pp. 90-91) elas representam o processo de progressiva institucionalização da sociedade internacional onde os Estados partilham valores e interesses comuns. Essa institucionalização seria, teoricamente, uma forma de esbater ou de minimizar a anarquia prevalecente no sistema internacional defendida por autores que se inscrevem no âmbito da teoria realista das relações internacionais, que excluem qualquer forma de cooperação e concertação de posições, tendo em vista a realização do bem ou interesse comum.

Em suma, o surgimento das Organizações Internacionais na cena política mundial pode ser sintetizado mediante a seguinte posição defendida pelo professor Inis Claude: “0 movimento das organizações internacionais [pode ser visto] acima de tudo como um esforço por parte dos estados para modernizar, moldar e reequipar o sistema "multiestatal" adaptando-o às circunstancias cada vez mais difíceis e em transformação do séc. XX (...)" (CLAUDE, 1986, pp. 4-5 apud SARAIVA, 2001, p.16).

Portanto, parece não sobrar dúvidas de que as crescentes transformações operadas no sistema internacional desde o final da I Guerra Mundial motivaram a criação dos assim chamados grandes espaços globais e regionais, que funcionariam como autênticas instâncias de partilha e concertação de interesses e valores comuns entre os membros componentes.

Tendo em conta a emergência desses novos atores situados a vários níveis de governança, este texto procura analisar a cooperação multilateral enfocando mais na perspectiva político-econômica da qual se destaca a ajuda pública aos países em desenvolvimento, concretamente à Cabo Verde. Assim, o texto se debruça sobre organizações internacionais de âmbito global como a ONU e o BM e organizações internacionais de âmbito regional como a UE, no sentido de averiguar as suas influências no processo de desenvolvimento de Cabo Verde.

Quanto à operacionalização desses grandes espaços internacionais, convém realçar o caráter polissêmico das Organizações Internacionais, pois elas têm sido, desde a sua emergência no cenário mundial ocorrida no século $\mathrm{XX}$, objetos de várias conceituações e estudos acadêmicos e empíricos motivados pelo interesse de se perceber a sua natureza, amplitude e alcance num mundo multipolar cada vez mais globalizado onde tudo repercute em tudo. Nesta senda, e não obstante as múltiplas definições 
avançadas pela literatura da área, as Organizações Internacionais podem ser entendidas como um "sistema formal de regras e objetivos, um instrumento administrativo racionalizado" (SELZNICK, 1957, p. 8 apud ARCHER, 2015, pp. 1-2) visando alcançar metas e objetivos traçados coletivamente ou com participação de diversas entidades que a compõem. Por outras palavras, elas se referem a entidades constituídas por Estadosnacionais (entenda-se países) que voluntariamente decidem integrar determinadas organizações com vista à perseguição de objetivos ou interesses comuns mediante a cooperação e concertação de posições ou vontades entre os membros.

Esta definição coloca as Organizações Internacionais como entidades que a par do Estado são, de jure e de facto, reconhecidas como atores de direito internacional para atuar em áreas das quais os Estados decidem livremente transferir competências (decisórias, regulatórias ou monitórias) que antes estavam sob sua tutela, tendo em vista a maior racionalização dos procedimentos e formas de conduta.

De igual modo, elas dispõem de instrumentos e instituições que assemelham aos dos Estados nacionais e que os permitem distinguir das organizações não governamentais e outras instituições internacionais quais sejam: a constituição e outros instrumentos legais como assembleias, Conselhos e secretariados permanentes (ARCHER, 2015, p. 2), que lhes permitem discutir e concluir acordos internacionais com poder vinculatório.

Além da existência de instituições convencionais semelhantes às do Estadonacional, se destaca também a presença, nessas organizações, de órgãos e/ou programas especializados orientados especificamente para problemas sociais específicos dos quais o mundo enfrenta e clama pela sua completa resolução. Por exemplo, o PNUD (Programa das Nações Unidas para o Desenvolvimento) é um dos vários programas ou organismos especializados das Nações Unidas orientados para a resolução de problemas específicos, quais sejam: a pobreza, a fome, a corrupção entre outros relacionados com o desenvolvimento.

Assim, pode-se verificar que elas são entidades que se colocam nas interfaces dos Estados e que, embora não os substituam, contribuem de forma decisiva para a procura de soluções e/ou respostas para os diversos e complexos problemas globais que só os Estados não conseguiriam, pois estes se tornaram entidades pequenas de mais para os 
grandes problemas mundiais e grandes de mais para os pequenos problemas locais (MALTEZ, 1999, p. 54).

\section{ORGANIZAÇÕES INTERNACIONAIS E AJUDA PÚBLICA AO DESENVOLVIMENTO}

A Ajuda Pública ao Desenvolvimento (APD) é, habitualmente, vista como um subproduto da Nova Ordem Econômica Internacional (NOEI) que inclui, naturalmente, a transferência de recursos de um país para o outro com o intuito de promover o desenvolvimento do país receptor (MONTEIRO, 1997, p. 63). De fato, ela emerge no cenário internacional após a segunda metade do século XX quando as Nações Unidas, em reação ao problema do subdesenvolvimento que afeta parte substancial do planeta, sobretudo na África, consideraram a década de 1960 como a primeira década destinada ao desenvolvimento.

Assim, os fatos históricos e que antecederam esta decisão parecem remontar ao ano de 1958 - quando foi possível identificar a primeira tentativa de Auxilio Público ao Desenvolvimento saída duma reunião de Conselho Econômico das Igrejas e que viria a ser seguida pela resolução nำ1522 (XV) da Assembleia Geral das Nações Unidas ao decretar o seguinte:

(...) (n)a esperança de que a corrente de assistência e de capitais internacionais aumentaria de maneira apreciável por forma a atingir um por cento dos rendimentos nacionais dos países economicamente avançados (PALMA, 2006, p. 109).

Portanto, apesar das primeiras preocupações com a Ajuda remeterem-se às intenções expressas na criação da Carta das Nações Unidas em 1945 e ao Plano Marshall², elas não constituiriam ainda a APD nos termos em que foi definida, uma vez que as intenções previstas no Plano Marshall de apoiar a reconstrução da Europa devastada pela guerra tratavam-se fundamentalmente de pôr as estruturas já existentes a funcionar e não de transferências de recursos com o objetivo de promover o desenvolvimento sustentado.

\footnotetext{
2 Esse Plano refere-se a um conjunto de medidas econômicas desenvolvido pelo Governo dos Estados Unidos da América logo após a II Guerra Mundial (1939-1945) com o objetivo de reconstruir a Europa devastada pela guerra.
} 
Convém realçar que o Comitê de Ajuda ao Desenvolvimento (CAD) adoptou em 1972 uma definição segundo a qual considera a APD como sendo toda transferência de recursos (humanos, financeiros e materiais) que sob a forma de donativos ou empréstimos, é feita direta ou indiretamente pelos Estados fornecedores e pelos vários organismos multilaterais financiados pelos países fornecedores (CAD-OCDE, 2016) ${ }^{3}$.

Neste sentido, resulta claro que a APD apresenta suas especificidades próprias e se distancia de outros Programas ou Planos meramente conjunturais e que não tenham como objetivo central a promoção do desenvolvimento econômico dos países pobres. A Organização da Cooperação para o Desenvolvimento Econômico (OCDE) apresenta três características definidoras da APD quais sejam: (i) ser concebida por agências oficiais, isto é, por entidades oficiais do Estado fornecedor; (ii) intuito principal de permitir o desenvolvimento econômico e melhorar o nível de vida nos Países em Desenvolvimento (PED) e, (iii) no caso de empréstimos, incluir um elemento doação na ordem de $25 \%$ (CAD-OCDE, 2016) ${ }^{4}$.

Não obstante as múltiplas dinâmicas e transformações das quais o mundo vem passando desde a emergência da NOEI, não parece ter havido modificações ou alterações substancias nos critérios definidores da ajuda, o que sugere certa estabilidade ou consenso internacional com relação ao seu conceito. Por outro lado, e como sinaliza Hettne (1995), ela enquanto fator permanente das Relações Internacionais, é um fenômeno bastante novo, pois é produto das dinâmicas e transformações históricas que têm constituído o sistema internacional contemporâneo resultante da forte polarização política, social e econômica entre o Ocidente e o Oriente, bem como da crescente globalização e integração da economia mundial.

Portanto, o conceito de APD utilizado neste trabalho centra-se na definição clássica proposta e desenvolvida pelo CAD na qual abrange apenas fundos do setor público, neste caso, de forma multilateral (via Organizações Internacionais), descurando assim outros fluxos de Ajuda internacional ao desenvolvimento como são os casos dos fluxos privados e os provenientes de organizações não-governamentais.

\footnotetext{
${ }^{3}$ Ver o site oficial da OCDE disponível em: http://www.oecd.org/dac/, acessado em 08/05/17.

4 Para maiores informaçõeso, consultar a página da OCDE, disponível em: http://www.oecd.org/dac/stats/officialdevelopmentassistancedefinitionandcoverage.htm, acessado em 08/05/17.
} 


\section{INTEGRAÇÃO DE CABO VERDE NAS ORGANIZAÇõES INTERNACIONAIS: CONTEXTO HISTÓRICO, SOCIAL E POLÍTICO.}

A integração de Cabo Verde nos diversos e quiçá contrastantes Organismos Internacionais surge na sequência do processo revolucionário iniciado nos primórdios de 1960 e que culminou com a descolonização do país em 1975. Convém realçar que o país esteve desde o seu achamento e povoamento em 1460 e 1462 respectivamente (CARREIRA, 1983) até 1974 sob o domínio colonial português que exercia o controle político à semelhança de outras colônias africanas sob sua tutela.

Assim, no plano internacional, vivia-se num contexto politicamente tenso e conturbado marcado pela Guerra Fria e, bem assim, pela disputa ideológica dos blocos socialista e capitalista que procuravam expandir suas esferas de influência política e, no plano nacional, assistia-se a emergência de um modelo político monopartidário ${ }^{5}$, que acabaria por conduzir os destinos do país durante quinze anos, ou seja, desde a independência nacional em 1975 até a abertura política ocorrida no início de 1990.

Contudo, a emergência do pós-colonialismo em Cabo Verde expôs, logo a seguir, graves fragilidades sociais e econômicas de um país confrontado com duras condições existenciais e que levaram renomados teóricos internacionais a considerá-lo como inviável ${ }^{6}$, tendo em conta o estado das finanças públicas deixado pela então potência colonizadora. A este contexto socioeconômico periclitante e de grande adversidade a nível interno e que viria a ditar as principais estratégias políticas gizadas pelo novel Estado, se junta um contexto internacional marcado pela grande incerteza e jogos de interesse protagonizados pelos principais blocos políticos em confronto.

\footnotetext{
${ }^{5}$ Sistema Político assente no Partido Único. Este sistema foi dominante, sobretudo, na África Portuguesa PósColonial que pretendia assim eliminar todas as formas de dominação capitalista e imperialista sobre seus territórios. Em Cabo Verde, o Partido Africano da Independência de Guiné e Cabo Verde (PAIGC) assumiu o Poder ao reivindicar a legitimidade histórica de ter participado na luta pela Libertação Nacional nas matas da Guiné-Bissau.

${ }^{6}$ A tese da (in) viabilidade do Estado de Cabo Verde foi subscrita por Henry Kissinger, um dos reputados teóricos da política externa norte-americana no período compreendido entre 1968-1976, na qual teria defendido que um Estado que apresentasse um PIB per capta inferior a 270 dólares dificilmente reuniria as condições para ser independente.
} 
Em face dessa grande polarização, a solução encontrada foi pragmática, ou seja, a de não se posicionar expressamente a favor de um ou de outro bloco e, consequentemente, Cabo Verde abraçou o "movimento dos não alinhados" (LOPES, 2012) saído da Conferência de Bandung realizada em 1955 e no âmbito da qual os países afroasiáticos decidiram cooperar entre si, no sentido de se manterem coesos ante a pressão e influência das superpotências em contenda.

Esse pragmatismo corporificado na política do não alinhamento levou a que Cabo Verde se relacionasse com todo o mundo, procurando assim múltiplos espaços de ancoragens no plano internacional com vista a se beneficiar das vantagens e, assim, perseguir o desenvolvimento.

Portanto, nos parece evidente que terá sido neste quadro de busca constante de múltiplas ancoragens, consubstanciada numa estratégia que elege e privilegia o multilateralismo como uma orientação estratégica, no sentido de afirmar relações de parceria e cooperação com diversos atores, que se enquadra a integração do país nos assim chamados "grandes espaços supranacionais globais e regionais" (BALÃO, 2008, p. 365). A parpar dos Estados individualmente considerados, esses espaços passaram a exercer grande influência nas políticas de cooperação para o desenvolvimento a nível mundial.

O excerto que se segue é revelador do quão importante foi e continua sendo para Cabo Verde a busca de diversas parcerias estratégicas, quer com seus vizinhos próximos, quer com vizinhos longínquos, na procura de soluções que permitam suprir suas múltiplas dificuldades e carências de ordem econômica e financeira decorrentes de sua vulnerabilidade endêmica e inexistência de recursos minerais:

(...) desde o povoamento, iniciado pouco depois do achamento na segunda metade do século XV, os habitantes das ilhas e seus governantes diretos foram, como continuam sendo, protagonistas de uma epopeia que tem como leitmotiv a busca de ancoragens continentais e parcerias estratégicas com os seus vizinhos próximos (África), periféricos (Europa) e longínquos (Estados Unidos da América), no contexto fronteiriço do Atlântico (MONTEIRO, 2004, pp. 19-30).

Essa saga pela busca de múltiplas ancoragens não se limitou apenas ao estabelecimento de boas relações bilaterais ao nível das entidades estatais, mas com a emergência da Nova Ordem Econômica Internacional no pós II Guerra Mundial logo se 
estendeu a entidades multilaterais compostas por Estados que livremente decidiram transferir parte de suas competências para atores atuando a vários níveis.

Assim, se justifica o fato deste pequeno arquipélago plantado no oceano Atlântico médio pertencer a todas as organizações supranacionais de âmbito global e regional referentes à região onde está localizado e estar ancorado a uma Organização Supranacional Regional fora da sua localização geográfica, como a União Europeia, mediante o acordo de Parceria Especial?

Subjacente a essa saga de busca de ancoragens múltiplas radica a demanda pelo desenvolvimento da qual tem sido fortemente dependente e/ou influenciado pela conjuntura internacional, com uma dinâmica que é induzida pelos fluxos (remessas e ajuda) que recebe e que, na perspectiva de João Estêvão (2004), combina as características de uma economia de rendas - (também designada de economia $\mathrm{MIRAB}^{8}$ ) e de uma economia de serviços (ESTEVÃO, 2004, pp. 139-157).

As múltiplas vulnerabilidades econômicas e sociais de que o país padece, associadas a um Estado de pequena dimensão, arquipelágico, insular, diasporizado e exíguo (MOREIRA, 1996, pp. 260-261) levaram à classe política cabo-verdiana de então a traçar, logo após a sua independência, uma Política Externa orientada para o desenvolvimento, ou seja, para a necessidade do país buscar recursos exógenos para colmatar as debilidades estruturais existentes no plano interno.

Nesta ótica, o Primeiro Plano Nacional de Desenvolvimento de 1982 (I PND) levado a cabo pelo então Partido Único no Poder considerava que a economia caboverdiana funcionava tendo por base a "reciclagem das transferências". (CABO VERDE, 1983, p. 57) quer no tocante à APD, quer em relação às remessas da vasta comunidade cabo-verdiana espalhada pelo mundo.

\footnotetext{
${ }^{7}$ O Acordo de Parceria Especial entre Cabo Verde e União Europeia foi assinado a 19 de novembro de 2007 após uma intensa negociação entre as autoridades cabo-verdianas e europeias sob o argumento de que ambas as entidades partilham cultura e valores comuns. 0 referido acordo assenta-se em seis pilares, quais sejam: (i) Boa Governação; (ii) Segurança/Estabilidade; (iii) Integração Regional; (iv) Convergência técnica e normativa; (v) Sociedade do conhecimento e, (vi) Luta contra a pobreza e Desenvolvimento.

${ }^{8}$ Esta expressão tem sido usada para designar as economias cujo funcionamento se baseia, essencialmente, nos fluxos de remessas de emigrantes e ajuda pública ao desenvolvimento. 0 termo MIRAB foi cunhado por G. Bertram e R. Watters e corresponde a um acrónimo em que MI significa migrações, R remessas, A ajuda e B burocracia (ação do Estado). Para informação mais detalhada, Cfr. BERTRAM, G. e WATTERS, R. F. (1985).
} 
Cientes das limitações e esgotamento deste modelo de desenvolvimento marcadamente tradicionalista e centralista, a classe política de então procedeu, nos finais da década de 1980, a uma reorientação da estratégia voltada para as orientações e recomendações emanadas do Consenso de Washington (FMI e BM), que apelava aos Países em Desenvolvimento para a importância da redução do papel do Estado no controle social visando, deste modo, a libertação do mercado, a estabilização macroeconômica e a orientação da produção para as exportações, de forma a torná-las no motor do crescimento econômico.

Neste sentido, o II Plano Nacional de Desenvolvimento (1986-1990) legitimava essas recomendações ao incorporar a reforma do setor econômico baseada nesses princípios, que doravante seriam encarados pela comunidade internacional como os principais vetores a ter em consideração na atribuição da ajuda, pois alimentavam a crença amplamente divulgada de que eles seriam capazes de resolver o problema de desenvolvimento socioeconômico. Note-se que esta situação se coloca após duas décadas de fracasso no que tange ao cumprimento de objetivos de desenvolvimento propostos pelas Nações Unidas.

Por outro lado, e pela primeira vez, a concessão da ajuda multilateral passou a estar associada aos condicionalismos de ordem econômica orientados para "a estabilização financeira e para o ajustamento estrutural com base nos Programas de Ajustamento Estrutural" (PALMA, 2006, p. 51).

Ora, isto motivou o Governo de então, ainda durante a vigência do Partido Único, em meados dos anos 1980, a introduzir algumas reformas administrativas, no sentido de possibilitar uma liberalização gradual da economia, com medidas de apoio ao setor privado associadas a financiamentos a pequenas unidades empresariais e à consequente redução do peso do Estado na atividade econômica. Essa redução buscava eliminar as barreiras internas que dificultam a eficácia da ajuda, e assim contribuir para a criação de um ambiente político-institucional ao nível interno que, por um lado favorecesse a eficácia da ajuda (OECD, 2005) no processo de desenvolvimento e por outro, ao cumprimento dos critérios de atribuição de ajuda impostos pelas instituições financeiras.

Aliado aos condicionalismos de índole econômica na atribuição da ajuda a partir de meados da década de 1980, também se juntaram, a partir dos anos 1990, os de ordem 
política (CARDOSO, 2004, p.60). Estes assentes nos princípios universais da Democracia, dos Direitos Humanos e da Boa Governança, que passaram a constar como critérios fundamentais da atribuição da ajuda.

0 conceito da Boa Governança criado no início do referido decênio (1990) pelas principais instâncias financeiras internacionais (BM e FMI) veio enfatizar a necessidade de um novo paradigma político-ideológico no relacionamento da Sociedade Internacional com os países em desenvolvimento, no sentido de permitir um melhor aproveitamento das ajudas concedidas, e assim, contribuir para a promoção do desenvolvimento econômico e social equilibrado das localidades e da melhoria de condições de vida da população.

Este novo paradigma faz assentar o essencial da sua argumentação nos princípios da transparência/abertura, eficácia/eficiência, prestação de contas, participação e coerência de modo a tirar o máximo partido das ajudas externas visando à salvaguarda dos interesses comuns de toda a coletividade, em detrimento dos interesses e projetos individuais de uma minoria que detém o poder político.

Nesta lógica, as principais instâncias financeiras ao nível mundial têm sido orientadas, a partir dos anos 1990, neste sentido e daí a necessidade premente dos países dependentes da ajuda externa, como é o caso de Cabo Verde, de reestruturar seu sistema político e econômico no sentido de adequar suas políticas e planos estratégicos às exigências liberais defendidas e sustentadas pelas principais agências financiadoras do desenvolvimento.

Durante a década de 1990 notou-se, claramente, a incorporação destas orientações na agenda política governativa, isto é, no processo legislativo e na formulação de políticas incluídas nos vários Programas de Governo e nos diversos Planos Nacionais de Desenvolvimento levados a cabo pelos sucessivos governos com a finalidade de se criar um quadro macroeconômico e político que favorecesse uma melhor aplicação das políticas e, consequentemente, promovesse melhorias nas condições de vida da população traduzidas na redução da pobreza e da fome extremas, das assimetrias regionais e locais, no investimento no capital humano, no reforço das capacidades locais e regionais com base nos princípios de subsidiariedade e solidariedade. Aliás, esses 
princípios constituem também as principais orientações e prioridades do Comité de Ajuda ao Desenvolvimento (CAD).

Terá sido neste contexto que se deu prosseguimento, durante este período, a um amplo programa de reformas socioeconômicas que incluía a privatização de empresas públicas nos mais diversificados setores da atividade econômica, quais sejam os da comunicação (CV TELECOM), da energia e água (ELETRA), de combustível (ENACOL) e os ligados à gestão dos portos e aeroportos.

Neste sentido, as Grandes Opções do Plano (1997-2000) definidas pelo II Governo da II República refletiam essas reformas neoliberais apregoadas pelas instituições financeiras, ao sintetizar o desenvolvimento através da "inserção dinâmica no sistema econômico mundial" (ESTEVÃO, 2004, p. 145), permitindo, assim, ao país aproveitar o potencial de oportunidades que a economia mundial oferece: o Investimento Direto Estrangeiro (IDE), a Integração Regional e a procura de parcerias estratégicas para o desenvolvimento do arquipélago.

\subsection{O BANCO MUNDIAL}

As relações entre Cabo Verde e Banco Mundial parecem ter sido intensificadas a partir do decênio de 1990 - altura em que o arquipélago abandonou o modelo econômico assente na direção e planificação centralizadas e adotou um novo modelo de crescimento econômico com base nos fundamentos e pressupostos do mercado. Por outro lado, e em face ao fracasso das medidas constantes do Programa de Ajustamento Estrutural (PAE) em muitos Estados africanos durante a década de 1980, o BM, no seu primeiro Relatório sobre a África Subsaariana, datado de 1989, chamava atenção para as questões da (Boa) Governança considerada como uma das principais ferramentas no combate à corrupção política, ao nepotismo, às crises sócio-políticas e econômicas que assolavam esses países e que, por via dessa razão, impediam o desenvolvimento econômico e social dos mesmos e, em última instância, o bem-estar das pessoas que neles se encontravam vinculados.

Desde essa altura, o BM incluiu na sua Agenda Política esta abordagem e, assim sendo, a sua intervenção ao nível da APD passou a ser, crescentemente, condicionada a 
fatores ligados à Boa Governança quer nos aspectos políticos, quer econômicos e sociais dos países receptores da APD.

Por essa razão, já nos anos 1990 o BM impôs a esses países uma série de condicionalismos que passariam pelas reformas a diversos setores do tecido social, designadamente: (i) a Reforma da Administração Pública no âmbito da qual se incluía: a) os pacotes de privatização das empresas públicas permitindo, deste modo, reduzir o peso do Estado na atividade econômica e assim estimular/incentivar a iniciativa privada e o setor privado como o principal motor do crescimento econômico e social e, em última análise, do desenvolvimento desses países; b) a prestação de serviço público de qualidade ancorada nos princípios da transparência e responsividade e aliada a garantia de maior eficácia e eficiência na gestão dos recursos públicos, o que tem vindo a ser, no decurso do último terço do século XX, uma prática recorrente e inteligível nos discursos dos atores multilaterais e, por conseguinte, legitimadoras da APD Multilateral.

Já o segundo condicionalismo (ii) prescrevia a necessidade do estabelecimento de uma estrutura e/ou quadro legal (legal framework) para o desenvolvimento do qual os princípios do Estado democrático de direito surgem como elementos catalizadores do desenvolvimento sustentado. Por sua vez, o terceiro (iii) assenta suas bases numa cultura de prestação de contas (accountability) procurando fortalecer as instituições como forma de torná-las melhor habilitadas na prossecução dos seus objetivos, por um lado, e conferir maior responsabilidade aos líderes governamentais, procurando, deste modo, desenvolver uma capacidade institucional que lhes possibilitassem ter um comportamento de respeito e compatível com as leis institucionais que, se esperam ser de transparência, rigor, cumprimento das normas e de isenção, por outro.

O quarto (iv) e último condicionalismo assenta-se sobre a importância dos princípios da transparência e da informação enquanto vetores essenciais e de suporte aos programas de comunicação social, por um lado, e enquanto linhas orientadoras do Governo na divulgação e/ou publicação de dados estatísticos, principalmente, a publicação anual do Orçamento do Estado, por outro.

Tendo em consideração essas reformas propostas pelo BM [que, no fundo, constituem as principais componentes da (Boa) Governança - considerada, a par da importância da Democracia e dos Direitos Humanos -, como um dos pilares essenciais da 
condicionalidade política da APD no contexto dos países em desenvolvimento], as linhas de orientação estratégica do desenvolvimento das ilhas plasmadas nos diversos documentos de orientação estratégica ${ }^{9}$, designadamente, os Programas do Governo, os Planos Nacionais de Desenvolvimento (PND) e as Grandes Opções do Plano (GOP) dos sucessivos governos têm vindo a ser, desde o início dos anos 1990, crescentemente direcionadas neste sentido.

As tabelas abaixo nos oferecem uma perspectiva de como tem sido o financiamento do BM ao país e de quais áreas ou setores socioeconômicos tem merecido maior atenção dessa instituição financeira mundial na atribuição da ajuda.

Tabela 1: Projetos financiados pelo BM durante o período compreendido entre 1992-1999.

\begin{tabular}{|c|c|}
\hline Designação do Projeto & $\begin{array}{l}\text { Montante (Milhões de } \\
\text { USD) }\end{array}$ \\
\hline Projeto de Privatização e Assistência Técnica & 4.2 \\
\hline Projeto de Transportes e Infraestruturas & 12.5 \\
\hline $\begin{array}{l}\text { Projeto de Reforma do Setor Público e Crédito de } \\
\text { Construção das Capacidades }\end{array}$ & 8.1 \\
\hline Projeto de Educação e Formação Profissional & 11.5 \\
\hline $\begin{array}{l}\text { Projeto de Reestruturação Institucional para a Promoção } \\
\text { do Setor Privado }\end{array}$ & 11.4 \\
\hline Projeto de Energia e Água & 17.5 \\
\hline Projeto de Apoio à Reformas Econômicas & 30.0 \\
\hline Projeto de Privatização e Assistência Técnica II & 9.0 \\
\hline Total & 92.7 \\
\hline
\end{tabular}

9 Todos esses documentos têm destacado e enaltecido a importância da Boa Governança enquanto recurso estratégico que possibilite o desenvolvimento sustentado e equilibrado do país. Para uma análise e visão detalhadas desses documentos, veja-se a página oficial do Governo de Cabo Verde in: http://www.governo.cv/. 
Tabela 2: Projetos financiados pelo BM durante o período compreendido entre 2001-2010

\begin{tabular}{|c|c|}
\hline Designação de Projeto & $\begin{array}{l}\text { Montante (Milhões de } \\
\text { USD) }\end{array}$ \\
\hline Crescimento e Competitividade & 14.5 \\
\hline VIH/SIDA & 14.0 \\
\hline Infraestruturas e Transportes & 5.0 \\
\hline Sector Rodoviário & 20.0 \\
\hline Desenvolvimento do Setor Social & 4.0 \\
\hline Ajustamento Estrutural & 19.0 \\
\hline Estratégia de Crescimento e Redução da Pobreza & 60.0 \\
\hline $\begin{array}{l}\text { Construção das Capacidades (capacitação) e Governança } \\
\text { Econômica }\end{array}$ & 4.5 \\
\hline Crédito de apoio à redução da pobreza VI & 10.0 \\
\hline Total & 151.0 \\
\hline
\end{tabular}

Tabela 3: Projetos financiados no período de 2011 a 2016.

\begin{tabular}{l|c}
\hline Designação de Projeto & $\begin{array}{l}\text { Montante (Milhões de } \\
\text { USD) }\end{array}$ \\
\hline Projeto de apoio ao setor das estradas & 10.0 \\
\hline $\begin{array}{l}\text { Projeto para a recuperação e reforma do setor da } \\
\text { eletricidade }\end{array}$ & 53.5 \\
\hline Crédito de apoio à redução da pobreza (PRSCVII) & 12.0 \\
\hline Projeto de reforma do setor do transporte & 19.0 \\
\hline Crédito de apoio à redução da pobreza (PRSCVIII) & 15.5 \\
\hline Crédito de apoio à redução da pobreza (PRSCIX) & 10.0 \\
\hline Sistema de distribuição de energia solar & 1.0 \\
\hline Desenvolvimento turístico & 5.0 \\
\hline Total & 126.0 \\
\hline
\end{tabular}


Fonte: site oficial do BM disponível em: http://projects.worldbank.org/search?lang=en\&searchTerm=\&countrycode exact=CV consultado em 10 de junho de 2017.

Essas tabelas mostram que as intervenções financeiras do BM ao nível da APD têm seguido estritamente a retórica e o discurso legitimador, no que concerne às reformas neoliberais veiculadas e defendidas pelo consenso de Washington a partir dos finais de década de 1980.

O fato de o país incorporar, sem hesitações, as políticas neoliberais e, assim, legitimar o discurso hegemônico tem lhe permitido granjear enorme reputação internacional ao ponto de ser considerado como "um bom aluno" (CARDOSO, 2004, p. 66), em decorrência de boas notas conseguidas nas avaliações das principais Instituições Financeiras mundiais das quais se incluem o BM.

Por outro lado, elas evidenciam um volume considerável da APD que, progressivamente, vem incrementando com o passar do tempo, contrariando a própria narrativa de crise econômica e financeira mundial que, a partir de 2008, tem constituído uma meta-agenda não apenas dos Estados territoriais, mas também das principais Instituições financiadoras do desenvolvimento.

\subsection{A UNIÃO EUROPEIA}

A intervenção da UE ao nível da APD a Cabo Verde parece ter a sua gênese no Tratado que institui a Comunidade Econômica Europeia (CEE) assinado em Roma, em 1957, no âmbito do qual terão sido consagrados na parte III, Título XVII do Tratado os rumos e as prioridades a seguir pela cooperação desta entidade (UE) com os países pobres em matéria de desenvolvimento, cujos objetivos teriam sido os seguintes: (i) o desenvolvimento econômico e social sustentável dos países em desenvolvimento, em especial dos mais desfavorecidos; (ii) a inserção harmoniosa dos países em desenvolvimento na economia mundial e, (iii) a luta contra a pobreza nos países em desenvolvimento (UNIÃO EUROPEIA, 1994, p.106).

Nesta linha, as Convenções de Yaoundé I (1963-1969) e II (1969-1975) institucionalizaram esta preocupação com o desenvolvimento dos países em 
desenvolvimento, especialmente com o grupo de países África, Caraíbas e Pacífico (ACP) através da criação, pela então Comunidade Econômica Europeia, de instrumentos técnicos e políticos, nomeadamente o Fundo Europeu de Desenvolvimento (FED) e outros instrumentos técnicos que permitam a concretização desses objetivos.

Embora não tendo sido abrangido pelas Convenções de Yaoundé (I e II) visto que o país ainda não tinha ascendido ao estatuto de país independente e soberano, estando, portanto, nessa altura, na situação de colônia/província ultramarina (MOREIRA, 1959), a intervenção financeira desta comunidade ao nível da APD a Cabo Verde - enquanto Estado independente e soberano - só veio a efetivar-se com a adesão deste à primeira Convenção de Lomé - sucessora das convenções de Yaoundé - assinada na cidade capital togolesa em 1977.

Sob os auspícios dos objetivos da cooperação aqui evidenciados, a intervenção comunitária a Cabo Verde corporizada nas Convenções de Lomé I, II, III, IV e IV bis, e Cotonou, representa um esforço da governança ao nível Supranacional Regional (esfera europeia) de traçar medidas de políticas que a médio e longo prazos contribuíssem para a alteração da situação de pobreza e penúria enfrentada pela população e que, consequentemente, impedia o desenvolvimento sustentado. Por outro lado, traduz, também, a necessidade premente de canalização dos fundos afetos às respectivas Convenções para áreas consideradas como prioritárias e estratégicas do desenvolvimento do país e, em última instância, para a concretização do tão ambicionado objetivo de desenvolvimento sustentado que pareceu ganhar novo fôlego a partir de 2015.

Dentre essas áreas, destacavam-se aquelas ligadas ao aperfeiçoamento dos sistemas de infraestruturas e transportes, de comunicação, saúde, educação, água, saneamento básico e integrado, eletrificação, produção agrícola, e reforço da capacidade nacional de gestão e execução de projetos, acabando assim, por se constituírem áreas consideradas como estruturantes e potenciadoras do desenvolvimento, em longo prazo, do arquipélago.

Assim, para a implantação desses projetos, o país contou, já durante a vigência da Convenção de Lomé I (1975-1980) da qual aderiu em 1977, com um considerável financiamento da CEE no valor de 4,0 milhões de euros, a que se juntou aos mais 37,5 
milhões de euros relativos à Convenção de Lomé II (1980-1985) para o período compreendido entre 1977 a 1985.

As tabelas seguintes ilustram a intervenção da esfera europeia em nível estatal/nacional tendo, em vista às grandes áreas definidas e consideradas como prioritárias no âmbito dos diversos acordos de cooperação que a União Europeia vem mantendo com Cabo Verde desde 1977.

Tabela 4: Intervenções Comunitárias em Cabo Verde no âmbito das Convenções de Lomé I e II correspondentes ao 4o e 5o FED (1977-1985)

\begin{tabular}{l|c}
\hline Infraestruturas & $\begin{array}{c}\text { Recursos afetos } \\
\text { (em milhões de euros) }\end{array}$ \\
\hline $\begin{array}{l}\text { Abastecimento de água e saneamento da cidade da Praia } \\
\text { Fornecimento de material para exploração hidro geológica } \\
\text { e recolha de lixo }\end{array}$ & 13.6 \\
Proteção dos solos da região de João Varela & 12.2 \\
Plano diretor da cidade da Praia & 18.4 \\
\hline Energia & \\
\hline Aumento da potência da central eléctrica da Praia & 21.8 \\
Reforço da capacidade da central elétrica do Mindelo & 16.3 \\
\hline Comunicações & 56.4 \\
\hline Melhoramento do aeroporto do Sal & 32.5 \\
\hline Construção do estaleiro naval do Mindelo & \\
\hline Indústria & \\
\hline $\begin{array}{l}\text { Construção de uma pequena unidade de produção de } \\
\text { cimento na ilha do Maio }\end{array}$ & 45.4 \\
\hline Comércio & \\
\hline Transferências STABEX10 & \\
\hline Formação & \\
\hline Concessão de bolsas e aquisição de equipamento escolar & \\
\hline
\end{tabular}

10 O STABEX é, no essencial, um sistema de estabilização de receitas de exportação de produtos agrícolas básicos, instituído pela Convenção de Lomé I, e corresponde a uma garantia monetária dada aos países ACP exportadores de produtos básicos com o objetivo de evitar os efeitos nefastos e indesejados da instabilidade da cotação internacional desses produtos [ex.: café, cacau, amendoim, banana]. Para mais informação cfr. MONTEIRO, Ramiro (1997, p. 143, p. 143). 


\begin{tabular}{l|c}
\hline Diversos & \\
\hline Micro realizações & 3.0 \\
Apoio à produção artesanal & 2.8 \\
Laboratório de solos e mecânica das rochas & 0.7 \\
Assistência técnica & 3.6 \\
Ajuda de urgência & 36.8 \\
Ajuda alimentar & 211.0 \\
Programa especial contra a fome & 4.5 \\
ONGs & 22.0 \\
TOTAL & 538.7 \\
\hline
\end{tabular}

Fonte: ABECASIS, 1985, p. 27.

Todavia, as relações de cooperação entre estes atores (UE e Cabo Verde) não se limitaram a estas duas Convenções de Lomé. Na verdade, a partir daí, as relações econômicas e políticas entre eles tornaram-se mais intensas, porquanto evoluíram para um patamar no qual se procedeu a um aprofundamento das intervenções comunitárias previstas no Lomé I e II.

Nesta linha, as Convenções de Lomé (III, IV e IV bis) representam a continuidade dessas primeiras intervenções consubstanciadas agora numa ação mais profunda e descentralizada ao nível dos projetos e programas acordados entre as partes.

As áreas abrangidas pelas Convenções de Lomé III (1985-1990), Lomé IV (19901995) e Lomé IV bis (1995-2000) terão sido, igualmente, as de infraestruturas de água e saneamento básico, energia, saúde e educação, (re) qualificação urbana e infraestruturas rodoviárias. Portanto, à semelhança da importância da infra estruturação do país dispensada por Lomé I e II, nota-se também, durante este período, uma clara opção pela criação de condições básicas (infraestruturas) que potenciassem um desenvolvimento e crescimento econômicos duradouros. Assim, da Convenção de Lomé II até à Convenção de Lomé IV bis, o país beneficiou de um montante total próximo dos 193,5 milhões de euros (COMUNIDADE EUROPEIA, 2001, p. 21).

Com o fim das Convenções de Lomé e a consequente assinatura do Acordo de Cotonou em 2000 entre o grupo de países ACP e a União Europeia, as relações de cooperação entre as partes parecem ter entrado numa fase na qual se pretendia 
ultrapassar a mera relação doador/beneficiário, isto é, numa fase onde a "parceria entre os iguais" se apresenta como uma das principais características do acordo ${ }^{11}$.

Para isso, Cotonou introduz na cooperação elementos inovadores em relação aos anteriores acordos combinando, deste modo, a APD com a dimensão política, os aspectos econômicos e comerciais em moldes muito distintos daqueles que eram passíveis de serem encontrados nos anteriores acordos e também aos novos atores não estatais, enfatizando, assim, o seu contributo em matéria de desenvolvimento.

Tabela 5: Áreas setoriais e montantes disponibilizados ao abrigo do Acordo de Cotonou correspondente ao 9.o FED (2000-2007)

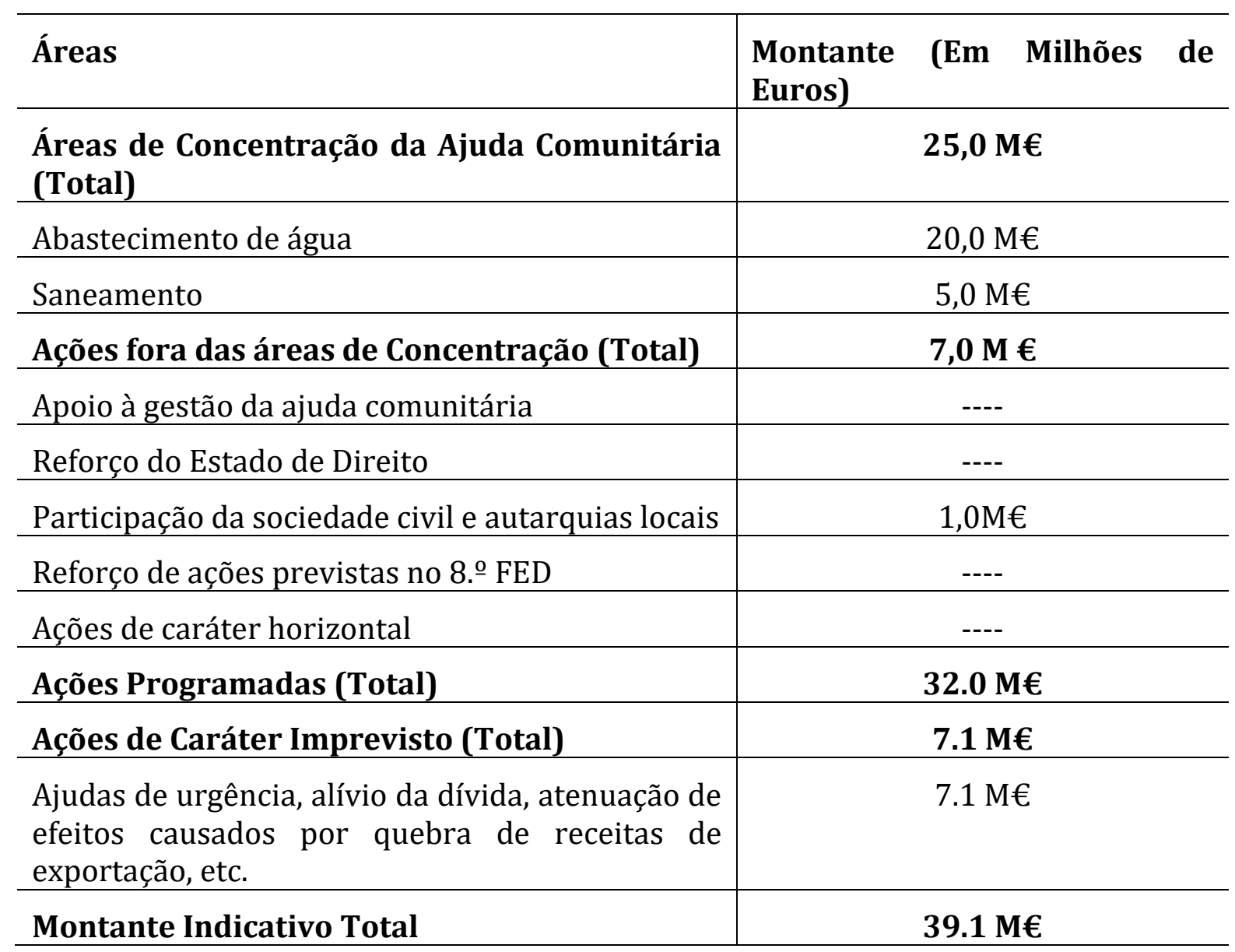

Fonte: Délégation de l'Union Européenne en République du Cap Vert. Disponível em: http://ec.europa.eu/europeaid/countries/cape-verde en?qt-node tabs country =1\#qtnode tabs country. Acessado em 05/06/17.

\footnotetext{
${ }^{11}$ O Acordo de Cotonou resulta da percepção de fracasso do cumprimento dos objetivos de desenvolvimento previsto nas convenções que o antecederam e, por isso, ele faz assentar suas bases numa relação de parceria que ultrapasse o tradicional quadro de cooperação ao eleger como princípios fundamentais a dimensão política; a extensão da parceria aos novos atores e a cooperação econômica e comercial.
} 
De igual modo, o 10. FED (2008-2013) vem dar seguimento aos programas de combate à pobreza e de promoção do crescimento sustentado e, para o efeito, assentouse em duas áreas consideradas fundamentais: (i) a da estratégia de crescimento e redução da pobreza, especialmente, nas áreas rurais e suburbanas onde as mulheres são chefes de família, bem como a promoção da boa governança e (ii) a de apoio ao desenvolvimento da Parceria Especial Cabo Verde/União Europeia.

0 montante disponibilizado foi de 51 milhões de euros destinados ao apoio macroeconômico às políticas setoriais e aos programas e projetos visando apoiar os setores de e fora de concentração da ajuda comunitária. Para além deste montante, o 10. o FED engloba ainda um montante de 3.1 milhões de euros destinados a fazer face às necessidades imprevistas, tais como ajudas em situação de emergência e apoios destinados a atenuar os efeitos indesejados e nefastos decorrentes da instabilidade das receitas de exportação.

Relativamente à primeira área de concentração da ajuda abrangida pelo 10. FED, a UE disponibilizou um montante de 32,6 milhões de euros canalizados diretamente para o Orçamento Geral do Estado. Em relação à segunda área de concentração da ajuda comunitária respeitante ao desenvolvimento da Parceria Especial Cabo Verde/União Europeia, o montante disponibilizado para a sua concretização foi de 11.5 milhões de euros.

Esta parceria surge na sequência do Acordo de Cotonou e representa a vontade política dos dois atores em estreitar as relações de cooperação assentes no diálogo político aprofundado, procurando com isso ultrapassar a velha lógica baseada na relação doador/receptor e, deste modo, centrar a cooperação em áreas de interesse comum, designadamente em matéria de segurança e desenvolvimento. A discriminação dos montantes e setores contemplados pode ser visto na tabela seguinte.

Tabela 6: Áreas setoriais e montantes canalizados ao abrigo do 10. FED (20082013)

\begin{tabular}{l|l}
\hline Áreas & $\begin{array}{l}\text { Montante (Milhões de } \\
\text { Euros) }\end{array}$ \\
\hline
\end{tabular}




\begin{tabular}{l|c}
\hline Áreas de Concentração da Ajuda Comunitária (Total) & $\mathbf{4 4 . 1} \mathbf{M €}$ \\
\hline $\begin{array}{l}\text { Apoio ao Documento de Estratégia de Crescimento e } \\
\text { Redução da Pobreza e ao Programa da Boa Governança }\end{array}$ & $32.6 \mathrm{M} €$ \\
\hline $\begin{array}{l}\text { Apoio ao desenvolvimento da Parceria Especial Cabo } \\
\text { Verde/União Europeia }\end{array}$ & $11.5 \mathrm{M} €$ \\
\hline Ações fora das áreas de Concentração (Total) & $\mathbf{6 . 9} \mathbf{M} €$ \\
\hline Facilidade de Cooperação Técnica & 1.8 \\
\hline Apoio aos Atores não Estatais & 2.0 \\
\hline Cooperação PALOP & 1.1 \\
\hline Reserva & 2.0 \\
\hline Ações Programadas (Total) & $\mathbf{5 1 . 0} \mathbf{M €}$ \\
\hline
\end{tabular}

Fonte: Délégation de l'Union Européenne en République du Cap Vert. Disponível em: http://ec.europa.eu/europeaid/countries/cape-verde en?qt-node tabs country =1\#qtnode tabs country. Acessado em 05/06/17.

Dando continuidade aos programas de cooperação com a União Europeia e com o término do $10^{\circ}$ FED, cuja implementação estendeu-se até 2016, foi assinado no mesmo ano um novo acordo de cooperação no âmbito do 11ํ FED para o período de 2016 a 2020 no montante de 50,0 milhões de euros. Além desse valor, foi disponibilizado ainda um montante de 5,0 milhões de euros destinados ao apoio institucional e à assistência técnica a que se juntou a um pacote de 7,0 milhões destinados à reabilitação da Ilha de Santo Antão na sequência das chuvas torrenciais de 2016.

As áreas contempladas no âmbito deste FED ligam-se diretamente ao setor do turismo, pois se destacam projetos voltados para a promoção e dinamização do turismo em diversas ilhas, colocando ênfase sobre as múltiplas dimensões que, modernamente, o termo encerra, quais sejam: o turismo solidário, cultural, ambiental, histórico, rural e ecológico.

\section{ANÁLISE EMPÍRICA}

A trajetória da APD exposta nas tabelas acima evidencia o quanto o financiamento externo multilateral a Cabo Verde foi e continua sendo imprescindível à materialização dos projetos de desenvolvimento concebidos sob a égide da governança multinível (MARKS, 1993). É, notoriamente, perceptível o quanto esse financiamento tem seguido 
uma trajetória ascendente desde os primeiros protocolos a esta data, embora tenha, ultimamente, registrado uma tendência de redução do montante tendo em conta a conjuntura internacional de crise econômica e financeira desencadeada em 2008 e que afetou as principais agências financiadoras do desenvolvimento.

De fato, Cabo Verde tem sido um dos principais beneficiários da APD multilateral muito por força do discurso legitimador da Boa Governança cunhada e desenvolvida pelo Banco Mundial no qual apela aos Estados em desenvolvimento a adotarem uma política consentânea com as principais orientações defendidas e sustentadas pelos diversos organismos que o integram e das quais foram descortinadas ao longo do texto.

A dimensão da Ajuda Pública a Cabo Verde torna-se melhor compreendida quando se percebe que, em termos do impacto na renda nacional bruta (GNI), ela representou 13,8\% em 2013; 13,0\% em 2014 e 9,8 em 2015 segundo dados mais recentes da OCDE ${ }^{12}$. Essa tendência de redução da APD de 2013 para 2015 pode ser explicada pelo fato do país ter alcançado, em 2008, o estatuto dos Países de Desenvolvimento Médio ${ }^{13}$ (PDM), o que implica na redução do montante da APD.

Portanto, a redução surge na sequência da transição do país decidida pela resolução 59/209 da Assembleia Geral das Nações Unidas, na qual estabelece um período de três anos no qual a graduação se tornaria efetiva e durante o qual se criariam as condições necessárias para que a graduação não represente retrocesso em relação ao processo de desenvolvimento em curso.

Todavia e a despeito do desenvolvimento sustentável, é inegável que a grande quantidade da APD a Cabo Verde, da qual as organizações internacionais representam apenas uma pequena parte se considerarmos outros fluxos que incluem, necessariamente, a ajuda bilateral no nível dos Estados individualmente considerados, não tem acompanhado uma qualidade desejável que permita ao país superar, a médio e longo prazo, o quadro da APD.

\footnotetext{
12 Para maiores informações conferir a página disponível em:

13 Em janeiro de 2008, as Nações Unidas decidiram promover Cabo Verde a País de Desenvolvimento Médio, deixando assim o grupo de Países Menos Avançados (PMA) a que estava incluído desde 1977. Essa graduação deve-se ao fato do país ter cumprido dois dos três critérios exigidos quais sejam: 0 índice de Desenvolvimento Humano situado à data na casa de 0,717 e o rendimento per capita ficando apenas por cumprir o índice da vulnerabilidade econômica, que permanece elevado.
} 
As tabelas e os dados apresentados denunciam um ciclo vicioso de ajuda que aponta, irreversivelmente, para aquilo que intelectuais na linha de Cardoso e Faletto (1970) denominam de teoria da dependência, pois determinadas políticas de desenvolvimento (das quais se incluem a APD), forjadas pelos grandes agentes decisivos à escala mundial contribuem mais para a reprodução do subdesenvolvimento do que propriamente para o desenvolvimento supostamente defendido por eles.

Não obstante o crescimento econômico acelerado durante a década de 1990 proporcionado, em grande parte, pelo incremento da APD - estima-se que o país cresceu de 1990 a 2000 a uma média de $6 \%$ ao ano ${ }^{14} .0$ país confronta-se com condições sociais e materiais ainda não superadas no domínio da educação, saúde, moradia e segurança o que pode comprometer o cumprimento de todos os objetivos de desenvolvimento sustentável no horizonte de 2030.

Por outro lado, essa forte dependência do financiamento externo pela via da APD vem obstaculizando as possibilidades de criação de uma cultura que encoraja e incentiva a produtividade e a criatividade nos diversos setores da atividade econômica criando assim as bases para um desenvolvimento sustentável.

A ausência de uma cultura de produtividade com base no aproveitamento das capacidades locais tem empurrado o país para níveis assustadores de endividamento público atingindo, segundo dados de 2015 publicados no outlook da OCDE, 125, 9\% do PIB. Cabe realçar que grande parte desse endividamento terá sido fruto de empréstimos concessionais que, aliás, representam um dos componentes da APD.

O excesso notório de endividamento público, associado ao alto nível da dependência do financiamento externo, demonstra que o modelo de desenvolvimento econômico até aqui traçado não é sustentável, haja vista a sua manifesta incapacidade de produção de riqueza que desestimularia o uso recorrente aos mecanismos e pressupostos subjacentes a APD. Por outro lado, uma análise apurada das tabelas listadas revela certa seletividade na atribuição da ajuda, acabando por ofuscar outras áreas e possibilidades de desenvolvimento que, por meio de uma metodologia diferenciada, poderiam produzir

\footnotetext{
${ }^{14}$ Ver o site do INE, disponível em: www.ine.cv, consultado em 10 de junho de 2017.
} 
melhores efeitos, permitindo assim ao país superar o mencionado ciclo vicioso da ajuda ao desenvolvimento.

Este contexto de seletividade o qual se junta uma abordagem que poderíamos chamar de modernista, porquanto, acredita que o desenvolvimento ocorre por etapas e por meio de infraestruturas modernas revela um problema que tem a ver com a enorme dificuldade de conciliar modernismo com desenvolvimento: ou seja, como otimizar ou aproveitar infraestruturas modernas criadas em benefício de melhorias de condições materiais e sociais das pessoas.

Este questionamento reforça o seguinte dilema do qual o país se confronta hoje: se, por um lado, já existem infraestruturas modernas e de acordo com padrão internacionalmente estabelecido, por outro lado, persistem ainda seguimentos substanciais de pobreza afetando, segundo dados mais recentes do Instituto Nacional de Estatística, 35\% da população cabo-verdiana, sendo $10 \%$ desse universo vivendo na extrema pobreza (INE, 2015).

Assim, o discurso "do bom aluno" fomentado por organizações como Banco Mundial, o qual tem servido como instrumento de legitimação da dominação, porquanto, sujeita o país a mecanismos de obediência e reciclagem das determinações, tem ignorado as condições materiais das pessoas e contribuído para uma visão de desenvolvimento assente na modernização de infraestruturas de duvidoso impacto na economia local.

Neste sentido, o célebre questionamento do fundador de políticas públicas, Harold Laswell (1936) permanece atual porque mais do que nunca interessa-nos saber quem se beneficia com essas políticas, como se beneficiam e porquê essas e não outras políticas. Portanto, tal questionamento é relevante uma vez que segmentos substanciais da população, conforme demonstrados pelos dados estatísticos oficiais. Permanecem, ainda, à margem dos benefícios resultantes dos projetos modernizantes o que indicia que só infraestruturas modernas sem o devido monitoramento e complementaridade com outras políticas não são suficientes para alcançar o desenvolvimento sustentável e com distribuição equitativa de rendimentos para toda a população.

\section{CONSIDERAÇÕES FINAIS}


A ajuda pública ao desenvolvimento em Cabo Verde tem sido historicamente um mecanismo segundo o qual o país abraçou logo a seguir a sua independência, dadas as múltiplas vulnerabilidades de que padece adveniente, em parte, da sua condição arquipelágica e de carência de recursos endógenos e, em parte, da difícil situação financeira deixada pelos portugueses à data da conquista da sua liberdade enquanto Estado.

Desde muito cedo o país firmou relações de parcerias com diversas e quiçá contrastantes organizações internacionais como forma de aceder aos diversos mecanismos de financiamento fomentados por essas organizações e, assim, procurar suprir as múltiplas limitações de financiamento ao desenvolvimento com as quais se confrontou desde os primórdios da independência nacional. Neste sentido, o país tem sido beneficiário de montantes substancias da APD, tornando-se um dos principais receptores da ajuda da sua sub-região oeste africana.

Todavia, se por um lado, a defesa do discurso legitimador da ajuda alimentado pelos principais agentes decisivos à escala global e regional permitiu a Cabo Verde granjear enorme reputação no cenário internacional pela boa gestão feita da ajuda, por outro, a manutenção desse mecanismo tem contribuído para uma enorme dependência da qual o país dificilmente conseguirá superar num horizonte temporal de curto e médio prazo.

Essa situação a qual tem desembocado num permanente ciclo vicioso tem impedido o país de procurar vias alternativas de desenvolvimento sustentadas em bases sólidas, permitindo assim a construção de perspectivas de resiliências fortes que o permita enfrentar situações de choques econômicos e financeiros, como aquelas ocorridas em 2008 e que tiveram enorme repercussão ou impacto em nível nacional/local.

Assim, se conclui pela validade do argumento, segundo o qual a APD multilateral tem contribuído para a perpetuação da dependência externa de Cabo Verde, no que tange ao financiamento do seu desenvolvimento, pois apesar de avultados recursos investidos no país concretamente, na criação e modernização de infraestruturas, ainda não conseguiu superar o convencionado quadro de ajuda pública ao desenvolvimento. 


\section{REFERÊNCIAS BIBLIOGRÁFICAS}

ABECASIS, António. A Comunidade Europeia e Angola, Cabo Verde, Guiné-Bissau, Moçambique e São Tomé e Príncipe. Comissão das Comunidades Europeias, Bruxelas, 1985.

AFONSO, Maria Manuela. Cooperação para o Desenvolvimento: Características, Evolução e Perspectivas Futuras. Lisboa: CIDAC, 1995.

ARCHER, Clive. International Organization. Fourth Edition. New York: Routledge 2015.

BALÃO, Sandra Maria Rodrigues. Globalização e Anti-Globalização no Mundo Contemporâneo. Uma Visão Analítica. Edição do Autor. Policopiada. Lisboa, 2008, [Tese de Doutoramento em Ciências Sociais na especialidade de História dos Fatos Sociais apresentada ao ISCSP-UTL].

BANCO MUNDIAL. Sub-Saharan Africa: From Crisis to Sustainable Growth: A LongTerm Perspective Study. The World Bank. Washington, D.C., 1989.

BANCO MUNDIAL. Country Cabo Verde Project. Disponível em: www.worldbank.org/en/country/caboverde/projects/all?qterm=\&lang exact=english. Consultado em 10/09/10.

BERTRAM, G. e WATTERS, R. F. "The MIRAB Economy in South Pacific Microstates", Pacific Viewpoint. Vol. 26, n. 3, 1985, pp. 497-519.

CABO VERDE-COMUNIDADE EUROPEIA. Documento de Estratégia de Cooperação para o Período 2001-2007. DEV/202/2001-PT.

CARDOSO, Fernando Henrique e FALETTO, Enzo. Dependência e Desenvolvimento na América Latina: Ensaio de interpretação sociológica. 7 a Edição. Rio de Janeiro: Editora LTC, 1970.

CARDOSO, Katia Aline Lopes Rodrigues. Diáspora: A (Décima) Primeira Ilha de Cabo Verde - A Relação entre a Emigração e a Política Externa Cabo-Verdiana. Dissertação de Mestrado, Lisboa: ISCTE, 2004.

COSTA, Suzano. Cabo Verde e a União Europeia: Diálogos Culturais, Estratégias e Retóricas de Integração. Dissertação de Mestrado em Ciência Política e Relações Internacionais, Lisboa: FDL/UNL, 2009.

ESTÊVÃO, João. “O Desenvolvimento de Cabo Verde e o Modelo de Integração Econômica Internacional". In Cabo Verde - Um Caso Insular nas Relações Norte-Sul. Revista Estratégia, n.o 20, 1.을 Semestre, IEEI, Principia, Lisboa, 2004, pp. 139-157.

INE. Resultados do III inquérito às despesas e receitas familiares, 2015. Disponível in: www.ine.cv. Acessado em 10 de junho de 2017.

KEOHANE, Robert 0. \& NYE, Joseph S. Power and Interdependence. 3rd Edition: New York, 2001.

LASWELL, Harold D. Politics: Who Gets What, When, How. Cleveland, Meridian Books, 1936. 
MALTEZ, José Adelino. "A Comunidade Mundial, o Projeto Lusíada e a Crise do Político". In: BARATA, Óscar Soares (coord.). Conjuntura Internacional 1999. Lisboa: ISCSP-UTL, 1999, pp. 49-80.

MARKS, Gary, "Structural Policy and Multi-Level Governance in the EC", in CAFRUNY, Alan W. e ROSENTHAL, Glenda, G. (Eds.). The State of the European Community, Boulder: Lynne Rienner, 1993, pp. 391-411.

MEYNS, Peter. "Cape Verde: An African Exception”. Journal of Democracy. Vol. 13, n. 3, 2002, pp. 153-165.

MONTEIRO, Fátima. Cabo Verde na Encruzilhada Atlântica. In: Cabo Verde - Um Caso Insular nas Relações Norte-Sul. Revista Estratégia, n. 20, Lisboa: Principia, 2004, pp. 1930.

MONTEIRO, Ramiro Ladeiro. A África na Política de Cooperação Europeia. Lisboa: ICSP-UTL, 1997.

MONTEIRO, Ramiro Ladeiro. África na Política de Cooperação Europeia. $2^{\text {a }}$ Edição atualizada, Lisboa: ISCSP-UTL, 2001.

MOREIRA, Adriano. Teoria das Relações Internacionais. Livraria Almedina. Coimbra, 1996.

MOREIRA, Adriano. A África e o Ultramar Português na Conjuntura Internacional. Instituto Superior de Estudos Ultramarinos, Vol. 8, n. ㅇ 2, 1959, pp. 7-20.

OECD. "Paris Declaration on Aid Effectiveness". Paris, 2005.

PALMA, Elisabete Cortes. Cultura, Desenvolvimento e Política Externa: A Ajuda Pública ao Desenvolvimento nos Países Africanos Lusófonos. Lisboa: IDI-MNE. Série D, 2006.

PIERE, Jon e PETERS, B. Guy. Governance, Politics and the State. London: Macmillan Press Ltd, 2000.

PNUD. Rapport National du Développement Humain Cap Vert 1999». Praia, 2000. Disponível em: http://www.undp.org/. Consultado em 09/09/10.

REPÚBLICA DE CABO VERDE, Primeiro Plano Nacional de Desenvolvimento 1982/85, Vol. 1 - Relatório Geral, Praia: Secretaria de Estado da Cooperação e Planeamento, 1983.

ROSENAU, James N. "Governance, Order, and Change in World Politics". In: ROSENAU, James N. e CZEMPIEL, Otto. Governance without Government: Order and Change in World Politics. Cambridge: Cambridge University Press, 1992, pp. 1-29.

SALCEDO, Carrillo J. A. El Derecho Internacional en un mundo en cambio. Madrid: Tecnos, 1984.

SARAIVA, Maria Francisca. Governance. Um caminho para a segurança cooperativa. Lisboa: ISCSP, 2001.

STRANGE, Susan. The Retreat of the State. The Diffusion of Power in the World Economy. Cambridge: Cambridge University Press, 1996.

TEKERE, Moses. Dimensões Políticas do Novo Acordo de Cotonou entre os Países ACP e a União Europeia. Centro de Estudos de Comércio e Desenvolvimento, [Trades Center], Harare, Zimbabwe, 2001. 


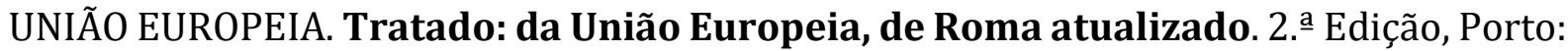
Porto Editora, 1994. 